\title{
Type 1 diabetes mellitus: psychosocial factors and adjustment of the pediatric patient and his/her family. Review
}

\author{
Marián Pérez-Marín, M.D., Irene Gómez-Rico, B.S., \\ and Inmaculada Montoya-Castilla, M.D. ${ }^{a}$
}

\begin{abstract}
Type 1 diabetes mellitus is the most common chronic endocrine disease in children, with a very low incidence in the first months of life and reaching its peak during puberty (10-15 years old is the age group with the highest incidence at the time of onset).

Based on the review of the scientific literature, our objective is to study the main psychosocial factors associated with the adjustment of these pediatric patients and their families. Research underscore the following risk factors: situational (stressful life events), personal (additional physical diseases, low self-esteem, emotional disturbances), and interpersonal (family breakdown and conflicts), and also protection factors (coping strategies, social support, fluent communication).

There is a pressing need to deal with the disturbances that affect these diabetic patients and their families, by implementing effective health care psychological interventions that take into account psychosocial factors associated with the course of type 1 diabetes mellitus.

Key words: type 1 diabetes mellitus, pediatrics, psychosocial impact, adjustment, family.
\end{abstract}

http:/ /dx.doi.org/10.5546/aap.2015.eng.158

a. Universidad de Valencia. School of Psychology. Department of Personality, Assessment and Psychological Treatments. Valencia, Spain.

E-mail Address: Marián Pérez-Marín, M.D.: marian.perez@uv.es

Funding:

This study was funded by a research aid granted by the Spanish Association of Clinical Psychology and Psychopathology in 2013.

\section{Conflict of Interest: None.}

Received: 4-17-2014 Accepted: 11-3-2014
Families with infants and adolescents with T1DM find themselves in a setting of rapid physical, psychological and social changes; T1DM may have a significant impact in their adjustment along this period of growth. As a result, many associated factors may disturb normal family functioning. The diagnosis of T1DM in this period, its later chronic course, the onset of complications and its complex treatment are a significant burden on children and their families, and result in a different personal and family functioning; apart from acquiring more knowledge on the disease and developing the necessary habits for its effective management. ${ }^{7}$ Maintaining an adequate metabolic control, a good quality of life and a flexible lifestyle seem to be the main challenges for youth with T1DM and their families. ${ }^{8}$

The American Academy of Pediatrics has pointed out that a purely medical management of T1DM is not enough; besides, it is necessary to improve the child's wellbeing or his/her health-related quality of life, enhance his/her adaptive capacity and his/her development and transition towards a healthy and productive adulthood. ${ }^{9}$

Therefore, we deem it necessary to identify the main factors that have an impact on the adjustment to established pediatric T1DM (in this context, adjustment means the extent to which an individual responds, physiologically and psychosocially, to the stress caused by the fact of having to live with a chronic disease).

Our study stems from the need to facilitate the adequate development of children diagnosed with T1DM 
and their families. Therefore, we present an article aimed at studying the main psychosocial factors related to the adjustment of these pediatric patients and their families. To this end, between 2013 and 2014 we conducted a comprehensive review of the existing scientific literature based on strict selection criteria that ensured the scientific relevance of the different document sources included in the analysis (reference articles in the field of medicine and the most important papers published along the past 10 years by distinguished authors and supported by the empirical evidence, quality and representativeness of their results) and using the most relevant databases in the field (TESEO, DISSERTATION ABSTRACT, ISBN, JCR, WOK, PROQUEST CENTRAL, PSYCINFO, SCOPUS, PUBMED, MEDLINE, ISOC, IME, PSICODOC, DIALNET, GOOGLE SCHOLAR and LATINDEX). Finally, more than 90 scientific documents were selected and analyzed in depth.

\section{Risk factors in the adjustment to pediatric type 1 diabetes mellitus}

A risk factor means a specific aspect of the lifestyle, an individual behavior, an environmental situation or a personal characteristic related to health related conditions, so that it is important to prevent or manage it. ${ }^{10}$ Risk factors may be classified as situational, personal or interpersonal.

a. Situational risk factors include characteristics related to the environment (external to the individual) or situations that have an impact on the course of a disease.

The American Diabetes Association ${ }^{11}$ points out that the main situational risk factors in pediatric chronic conditions include stressful life events (either physical or emotional), socioeconomic disadvantages, neglect or discrimination, and family unemployment.

b. Personal risk factors include individual endpoints of the patient that have an effect on the adjustment process.

Potential risks for the adequate evolution of patients with pediatric chronic diseases include the presence of additional physical diseases (especially, chronic and/or neurological conditions), learning difficulties, specific developmental delays, low intelligence, difficult temperaments, language and communication difficulties, repetitive academic failure, and low self-esteem. ${ }^{12}$

Besides, these young patients usually have emotional disturbances (fear, anxiety, depression, behavior or eating disorders) which have a negative impact on their well-being. ${ }^{13,14}$

The most common concerns regarding T1DM described by these patients include ${ }^{15}$ the responsibility for continuously managing or controlling T1DM, physical marks left behind by needle pricks, being constantly alert about the body response to insulin, emotional setbacks that depend on blood glucose levels, anxiety regarding the social or emotional status of their disease (especially fear of negative reactions by their friends) and, in general, the continuous thought of complications of their disease.

Pressures related to the management of T1DM may lead to major stress and psychological alterations in these children, which often result in poor metabolic control, non-compliance with treatment and, in the end, a worse adjustment. ${ }^{15,16}$

The main personal risk factors associated with a worse course of T1DM are an early diabetes onset, a longer course of T1DM, a history of severe hypoglycemia, and a worse metabolic control. ${ }^{8,17}$ Another important aspect related to stress and poor adjustment to T1DM is the high hospitalization rate of these patients, which is three times higher than that of the general pediatric population. ${ }^{18}$ Acute hospitalizations result in school absenteeism of patients, workplace absenteeism of family members, poor performance of all family members, a climate of family conflict, and increased morbidity and mortality. ${ }^{8,19}$

The diagnosis of T1DM is usually accompanied by a mild psychological crisis;, 6,20 approximately $36 \%$ of patients have some sort of psychiatric disorder in the first year. ${ }^{6,16}$ Although mild, these crises are usually predictors of a subsequent anxiety and/or depression event, ${ }^{6}$ and a lower self-esteem. ${ }^{3}$ In the second year, patients become more aware of the chronicity of their disease, its complications and the personal skills they will require to adequately manage such complications. ${ }^{16}$ Diabetic children tend to develop dependency, isolation and depression. ${ }^{20}$

c. Interpersonal factors refer to the significant characteristics of an individual's relationship with his/her family and closest social environment, which have an impact on his/her adjustment to the disease.

Pediatric T1DM accounts for a major reason of stress, which affects the entire family system. T1DM may be considered a "family disease." 21 Patients suffer from stress and have behavioral problems and a worse functional capacity, 
and as a result their families suffer from more stress and adjust poorly to the disease, and vice versa. Diagnosis and treatment of T1DM usually accounts for a traumatic event for parents, who often become angry and worried ${ }^{15,16}$ (for example: they feel impotence and insecurity regarding disease-related decisions, fear professional judgment regarding family or patient habits, have a tendency towards overprotection or excessive autonomy) and have significant stress symptoms. ${ }^{13,15,22}$

General risk factors observed in families of patients with pediatric chronic diseases include other family members with physical or psychiatric conditions, physical, sexual and/or emotional abuse, parents who are criminals or abuse substances, and the death of loved ones. ${ }^{12,23}$

An adequate social and family support system (both general and specifically related to T1DM) appears as the main factor to help these patients improve their quality of life, emotional wellbeing (including a lower incidence of anxiety and depression), self-care, treatment and metabolic control adherence, and to feel valued and protected by others. ${ }^{22,24-26}$

Studies have described a lower level of autonomy and more strictness as common characteristics of families with adolescents who suffer from diabetes. ${ }^{22}$ Excess family blending or cohesion, overprotection, strict rules and coping strategies, and difficulties to solve conflicts should be taken into account when aiming at enhancing families' capacity to adjust to complications typical of T1DM (for example, metabolic crises), together with the causes of stress distinctive of adolescence. ${ }^{27-29}$

Adolescents with T1DM who come from a broken or dysfunctional home or single parents have more depression and lower levels of general well-being. The presence of rejection or aggressive relationships and the sense of little emotional support are risk factors that hinder the adequate course of the disease. ${ }^{25,30}$ These patients have a higher chance of experiencing depression when they perceive a low level of specific family support. ${ }^{22}$ As a result, the most important risk factors for this population include intense, long-lasting and/or frequent conflicts between parents or among family members, family breakdown, incoherent or unclear parenting styles, excessive strictness or lack of family flexibility to adjust to the changing needs typical of childhood/adolescence or to the different situations related to the disease (nutrition and exercise recommendations, outpatient visits, hospital stays, etc.). ${ }^{27}$

\section{Protection factors in adjustment to pediatric type 1 diabetes mellitus}

Protection factors refer to those aspects that may safeguard individuals with a specific disease or that, ultimately, may reduce or mitigate its negative consequences. Overall, we should point out the following: ${ }^{10}$

a. Coping strategies (losses associated with chronic diseases are considered stressors that require coping with both the problem and emotions at different times. The first type of coping may serve better in situations that can be modified; while the second type, may be exercised in irreversible situations. Therefore, when adjusting to a disease, these two components play a differential role at different times, from anticipating a loss to overcoming it); or

b. Protection factors that originate from the study of risk factors (many risk factors may be considered inversely as protection factors: family support, employment, no financial difficulties, no previous pathologies, etc.); or

c. Factors detected based on the clinical experience (communication fluency, selfefficacy, feeling capable of caring for oneself and for the sick, ability to plan and solve problems, mental flexibility, finding sense in experiences).

The main protection factors that may help a child with diabetes adjust to his/her disease include a positive feeling of self-efficacy, feeling useful, being capable of self-care, adequate coping strategies, decision-making and problem-solving when dealing with the stress of a chronic disease, communication and planning skills, a good sense of humor, and the capacity for reflection..$^{23,31}$ In addition, overall self-esteem and social support have demonstrated a positive association with adjustment and a negative association with stress, ${ }^{26}$ therefore, both variables help to reduce stress and thus increase the chance of an optimal adjustment to T1DM during childhood. In turn, child and adolescent resilience appears to function as a buffer regarding the lack of glycemic control and self-care behavior in relation to T1DM. ${ }^{32}$

The main protection factors in pediatric T1DM are the presence and perception of family support. ${ }^{12}$ Patients with greater well-being are those who perceive that their families have a 
better capacity to adjust to T1DM consequences and to their growth, who are more cohesive and organized and, therefore, have fewer conflicts. ${ }^{22} \mathrm{~A}$ balanced family cohesion (which enables a stable and safe relationship with certain autonomy among family members) and a balanced family organization (without too much autonomy and excessive personal recommendations regarding personal objectives or goals) appear as related to a greater well-being, a lower level of anxiety and depression, more energy, a better diabetes management and less intergenerational conflicts. ${ }^{12,22,27,33}$

Finally, an adequate glycemic control since the onset of diabetes is associated with a favorable disease course, which helps to enhance patients' academic skills. ${ }^{34}$ In addition, a sense of control by patients and their families has been identified as a protection factor which increases their adjustment and functioning mechanisms in the case of diabetes. ${ }^{35}$

\section{CONCLUSIONS}

Our study shows that there is a pressing need to deal with the psychosocial aspects that affect children and adolescents with diabetes and their families, with a focus on what should become a public health priority. Thus, improving the health status of these patients should not be the only objective; it is also necessary to deal with these factors so that the costs incurred by these patients and their families are also reduced. For health care psychological interventions to be effective, psychosocial factors associated with T1DM should also be promoted by means of adequate campaigns.

\section{REFERENCES}

1. Mora Gómez-Calcerrada E, Beléndez Vázquez M, Ballester Herrera MJ, GiraltMuiña P, etal.Evaluación dela calidad de vida en niños y adolescentes con diabetes tipo 1 . AvDiabetol 2005;21(2):151-60.

2. DIAMOND Project Group. Incidence and trends of childhood Type 1 diabetes worldwide 1990-1999. DiabetMed 2006;23(8):857-66.

3. Martínez ChamorroMJ,Lastra MartínezI,Luzuriaga Tomás C. Características psicosociales de los niños y adolescentes con diabetes mellitus tipo 1. An Pediatr 2001;55(5):406-41.

4. Gómez-Rico I, Pérez-Marín M, Montoya-Castilla I. Diabetes mellitus tipo 1: breve revisión de los principales factores psicológicos asociados. An Pediatr (Barc) 2014 May 5. [Epub ahead of print].

5. Dantzer C, Swendsen J, Maurice-Tison S, Salamon R. Anxiety and depression in juvenile diabetes: a critical review. Clin Psychol Rev 2003;23(6):787-800.

6. Kovacs M, Ho V, Pollock MH. Criterion and predictive validity of thediagnosisofadjustmentdisorder:aprospective study of youths withnew-onset insulin-dependent diabetes mellitus. Am J Psychiatry 1995;152(4):523-8.

7. Hoey H. Capacitar a niños con diabetes y a sus padres. Diabetes Voice 2004;49:25-7. Available at: http:/ / www.idf. org/sites/default/files/attachments/article_269_es.pdf. [Accessed on: November 5, 2014].

8. Bollepalli S, Smith LB, Vásquez A, Rodríguez H, et al. Addressing the burdens of type diabetes 1 in youth. Clinical Practice 2012;9(4):409-24.

9. American Academy of Pediatrics Committee on Children with Disabilities and Committee on Psychosocial Aspects of Child and Family Health: psychosocial risks of chronic health conditions in childhood and adolescence. Pediatrics 1993;92(6):876-8.

10. Barreto-Martín P, Pérez-Marín M, Yi P. Predictors in complicated grief: supporting families in palliative care dealing with grief. En Chang E, Johnson A, eds. Contemporary and innovative practice in palliative care. Rijeka, Croatia: Intech; 2012.Págs.59-82.

11. American Diabetes Association. Executive summary: standards of medical care in diabetes-2012. Diabetes Care 2012;35(Suppl 1):S4-S10.

12. Hansson CL, Henggeler SW, Harris MA, Burghen GA, et al. Family system variables and the health status of adolescents with insulin-dependent diabetes mellitus. Health Psychol 1989;8(2):239-53

13 Whittemore R, Jaser S, Guo J, Grey M. A conceptual model of childhood adaptation to type 1 diabetes. Nurs Outlook 2010;58(5):242-51.

14. Zabala M, Vázquez Martínez O, Whetsell MV. Bienestar espiritual y ansiedad en pacientes diabéticos. Aquichan 2006;6(1):8-21.

15. Jacobson AM. The psychological care of patients with insulin-dependent diabetes mellitus. NEnglJMed 1996;334(19):1249-53.

16.Martínez Chamorro MJ, Lastra Martínez I, Luzuriaga Tomás C. Perfil psicosocial de niños y adolescentes con diabetes mellitus. Boletín de la Sociedad de Pediatría de Asturias, Cantabria, Castilla y León 2002;42:114-9.

17. Rewers A, Chase HP, Mackenzie T, Walravens P, et al. Predictors of acute complications in children with type 1 diabetes. JAMA 2002;287(19):2511-8.

18. Levine BS, Anderson BJ, Butler DA, Antisdel JE, et al. Predictors of glycemic control and short-term adverse outcomesinyouthwithtype1diabetes.JPediatr 2001;139(2):197-203

19. Tao B,Pietropaolo M,Atkinson M,Schatz D, etal. Estimating the cost of type 1 diabetes in the U.S.: a propensity score matching method. PLoS One 2010;5(7):e11501.

20. Grey M, Cameron ME, Lipman TH, Thurber FW. Psychosocial status of children with diabetes in the first two years after diagnosis. Diabetes Care 1995;18(10):13306.

21. Beléndez M. Estrategias de afrontamiento y bienestar emocional en padres y madres de niños y adolescentes con diabetes: diferencias de género. Ansiedad Estres 2012;18(23):177-86

22. De Dios C, Avedillo C, Palao A, Ortiz A, et al. Factores familiares y sociales asociados al bienestar emocional en adolescentes diabéticos. Eur J Psychiat (Ed Esp) 2003;17(3):171-82.

23. McDougall T. Mental health problems in childhood and adolescence. Nurs Stand 2011;26(14):48-56; quiz 58-60.

24. Skinner TC, John M, Hampson SE. Social support and personal models of diabetes as predictors of self-care and well-being: a longitudinal study of adolescents with diabetes. J Pediatr Psychol 2000;25(4):257-67.

25. Whittemore R, Kanner S, Grey M. The influence of family on physiological and psychosocial health in youth with 
type 1 diabetes: A systematic review. En Melnyk BM, Fineout-Overholt E, eds. Evidence-based practice in nursing and healthcare: a guide to best practice. Philadelphia: Lippincott Williams \& Wilkins; 2004.Págs.73-87.

26. Martínez Martínez B, Torres Velázquez LE. Importancia de la familia en el paciente con diabetes mellitus insulinodependiente. Psicol Salud 2007;17(2):229-40.

27. Hanson CL. Developing systemic models of the adaptation of youths with diabetes. En: La Greca AM, Siegel LJ, Wallander JL, Walker CE, eds. Advances in pediatric psychology: Stress and coping in child health. New York: Guilford; 1992.Págs.212-41.

28. Silverstein J, Klingensmith G, Copeland K, Plotnick L, et al. Care of children and adolescents with type 1 diabetes: a statement of the American Diabetes Association. Diabetes Care 2005;28(1):186-212.

29. Sánchez-Guerrero O, Romero A, Rodríguez V, Rangel B, et al. Adolescentes diabéticos: el problema de la no adherencia al tratamiento. Acta Pediatr Mex 2012;33(3):148-9.

30. Berg CA, Butler JM, Osborn P, King G, et al. Role of parental monitoring in understanding the benefits of parental acceptance on adolescent adherence and metabolic control of type 1 diabetes. Diabetes Care 2008;31(4):678-83.

31. Edgar KA, Skinner TC. Illness representations and coping as predictors of emotional well-being in adolescents with type 1 diabetes. J Pediatr Psychol 2003;28(7):485-93.

32. YiJP, Vitaliano PP, Smith RE, YiJC, et al. The role of resilience on psychological adjustment and physical health in patients with diabetes. Br J Health Psychol 2008;13(Pt 2):311-25.

33. Hauser ST, Jacobson AM, Lavori P, Wolfsdorf JI, et al. Adherence among children and adolescents with insulindependent diabetes mellitus over a fouryear longitudinal follow-up: II. Immediate and longterm linkages with the family milieu. J Pediatr Psychol 1990;15(4):527-42.

34. Hannonen R, Komulainen J, Riikonen R, Ahonen T, et al. Academic skills in children with early-onset type 1 diabetes: the effects of diabetes-related risk factors. Dev Med ChildNeurol 2012;54(5):457-63.

35. Cardarelli KM, Vernon SW, Baumler ER, Tortolero S, et al. Sense of control and diabetes mellitus among U.S. adults: a cross-sectional analysis. Biopsychosoc Med 2007;1:19. 